\title{
Haemoglobin Level in Children of a Northern District of Bangladesh
}

\author{
MN ABSAR
}

\begin{abstract}
Summary:
Objective: To find out the reference level of haemoglobin and other haematological parameters(PCV, MCV, MCH, MCHC, S. Iron and S. Ferritin) of the children of Northern area of Bangladesh and to see the relation of socio demographic features and other haematological parameters with haemoglobin level.
\end{abstract}

Methodology: Observational cross sectional study.

Setting: Outpatient department of Rangpur Medical College and outpatient department of eight Upozilla Health Complexes of northern Bangladesh.

Patients:300 clinically healthy 1yr. to 14yr. age children.

Outcome measures: Mean $\mathrm{Hb}$. level in age groups and influence of sex, age, economic status, parental education, nutrition and serum iron on level of $\mathrm{Hb}$. PCV, MCV, MCH, MCHC, S. Iron and S. Ferritin was estimated to see the confounders and if they are affecting $\mathrm{Hb}$. level significantly.

Introduction:

In preschool age $47.4 \%$ are suffering from iron deficiency anaemia. Prevalence in Asia is $65.5 \%{ }^{1}$. In Bangladesh prevalence in preschool age is $47 \%$ according to 2001 survey $^{2}$. To define anaemia WHO cut off value of haemoglobin is being used. But it is well known that normal level of haemoglobin in a population varies with age,gender, altitude, race and ethnicity. Lower level of haemoglobin has been observed in children of Asian and African origin in comparison with American and European origin ${ }^{3,4,5}$. Weihang et al concluded in their study that blood values differ by age ,sex and race. It was obvious that there was significant difference of Hb, PCV, $\mathrm{MCV}, \mathrm{MCH}, \mathrm{MCHC}$ values between white and blacks in all ages ${ }^{(6)}$. Normal haemoglobin level should be defined for each particular group of population in order to see the prevalence of anaemia in the particular population

Address of Correspondence: Prof. M. N. Absar, Professor of Paediatrics, Rangpur Medical College, Rangpur, Bangladesh

Received: 4 January, 2011

Accepted: 2 May, 2012
Results: Mean haemoglobin among study population was $11.4 \mathrm{gm} / \mathrm{dl}(\mathrm{SD} ; 1.07)$. Haemoglobin was normally distributed among the study population. Mean haemoglobin among age groups differed significantly. No significant difference in mean haemoglobin was observed among two sex groups.

Mean haemoglibin level corresponded well with WHO defined haemoglobin level in the same age group of children.

Conclusion: Reference level of mean $\mathrm{Hb}$. in the studied population is 11.4gm/dl(SD;1.07). Age affects the Hb. level but sex does't. Hb. level in this population is comparable with WHO reference value for this age.

Key ward: Reference level of haemoglobin, haemoglobin level in children, mean haemoglobin, racial difference in haemoglobin.

(J Bangladesh Coll Phys Surg 2012; 30: 127-131)

group. We have to know the haematological parameters in our children for better understanding of their normal growth and nutrition status.

\section{Methodology:}

Study was conducted in Rangpur district of Bangladesh. Children of 1 yr. to $14 \mathrm{yr}$. attending the out patient departments of Rangpur Medical College and eight upazilla health complexes were included in this study. Systematic random sampling was done. Chronic and recurrent illness and any inflammatory condition was excluded by history and clinical examination. Anaemia was screened out clinically. Nutrition status was determined by anthropometry and $\mathrm{Z}$ score of height for age and weight for age. Venous blood sample was collected and Hb., PCV, MCV, MCH, MCHC, S.Iron and S.Ferritin were estimated. Haemoglobin was done by cyanmethaemoglobin method and other haematological parameters were estimated by fully automated haematology analyzer; Sysmex XT - 1800i, Japan and Immulite - 1000 analyzer USA. Peripheral blood film 
was scaned by qualified haematologist to exclude the possibility of congenital haemolytic anaemia. Study was done during the period of January'08 to December'08. Sample size was 250 to give $95 \%$ confidence interval of 0.04 with standard error of 1.96 . It was rounded upward to 300 to reduce sample error.

\section{Result:}

Age of the study population ranges from 1.4 yr. to 14 yr. Mean age was 7 yr. with SD; $\underline{3} 3.12 y r$. Demography of the study population is as follows.

\section{Table-I}

Demography of study population
Parameters $\quad$ No(\%)

Age group:

$1-4$ yrs.

$4-9$ yrs.

$9-14$ yrs.

86(28.7)

Sex:

Female

Maternal education:

Illiterate

Primary

106(35.3)

64(21.3)

Secondary

Higher secondary

Occupation of the parents:

Labourer

Service

Business

82(27.3)

Other

15(5)

Total monthly family income(Taka):

Range

$1500-30000$

Mean(SD)

$5357.33( \pm 3675.797)$

Per capita monthly income(Taka*):

$<1000$

$1000-2000$

$2000-3000$

$>3000$

13(4.3)

$* 1 \$=70 \mathrm{Tk}$.

$\mathrm{Z}$ score(Weight for age): Mean Z score was $-2.3457, \mathrm{SD}=+5.45$.

$\mathrm{Hb}$. was distributed normally with no skew ness. Hb. level and other haematological parameters are given bellow(Table II). Haematological parameters were normal in comparison to their reference value, which indicates that the studied population was not anaemic.

Table-II

\begin{tabular}{lc}
\multicolumn{2}{c}{ Haematological parameters } \\
Parameters & Mean value(SD) \\
\hline $\mathrm{Hb}(\mathrm{gm} / \mathrm{dl})$ & $11.4 \pm 1.07$ \\
$\mathrm{PCV}(\%)$ & $36.324 \pm 3.31$ \\
$\mathrm{MCV}(\mathrm{fl})$ & $79.134 \pm .29$ \\
$\mathrm{MCH}(\mathrm{pg})$ & $24.82 \pm 2.59$ \\
$\mathrm{MCHC}(\mathrm{gm})$ & $31.29 \pm 1.85$ \\
S.Iron $(\mu / \mathrm{dl})$ & $59.72 \pm 32.94$ \\
S.Ferritin(ng/dl) & $59.4 \pm 52.79$ \\
\hline
\end{tabular}

In this population haemoglobin is distributed normally(Fig:1). There was no skewness. There was no significant difference in haemoglobin level between the male and female groups $(\mathrm{P}=0.65)$. Mean haemoglobin distribution in different age group differed significantly $(\mathrm{P}=.000)$. Factors those affected mean $\mathrm{Hb}$. level were father's education $(\mathrm{P}=0.01)$, Parental occupation $(\mathrm{P}=0.002)$, total monthly family income( $\mathrm{P}=0.014)$. $\mathrm{Z}$ score for weight for age was found to have no significant correlation with haemoglobin level of the study group $(\mathrm{r}=0.005, \mathrm{P}=0.927)$.

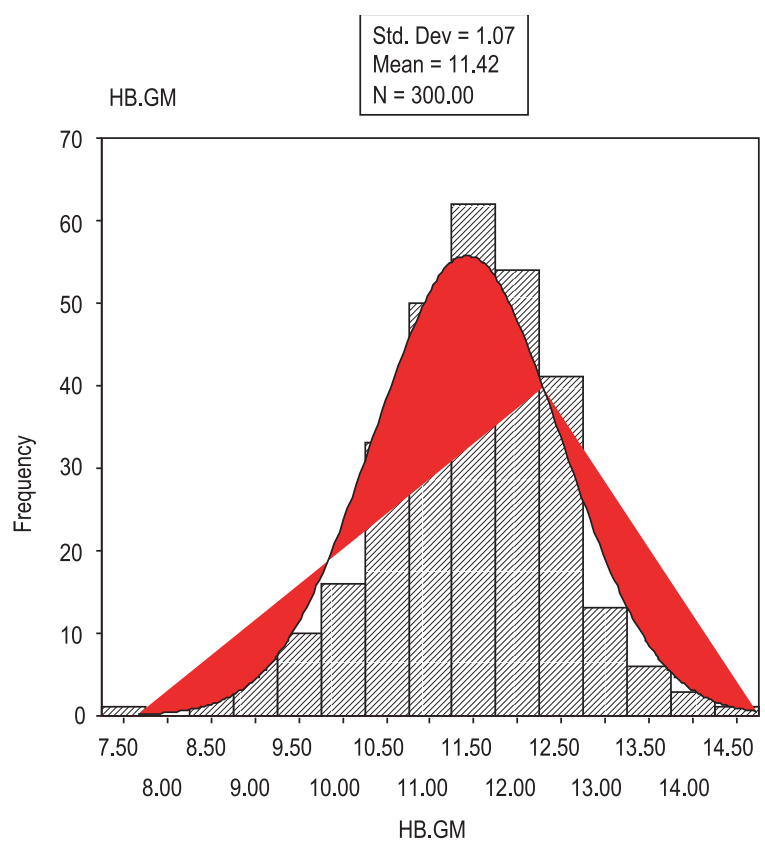

Fig-1: Distribution of haemoglobin in studied population 
There are high correlations of haemoglobin in the studied population with PCV, MCV, MCH, MCHC, S.Iron, but no correlation was found with S.Frritin. These are shown in Table-III.

Table-III

\begin{tabular}{lcc}
\multicolumn{3}{c}{$\begin{array}{c}\text { Correlation of } \\
\text { Hb with other Haematological } \\
\text { Parameters }\end{array}$} \\
& $\begin{array}{c}\text { Pearson } \\
\text { Correlation(r) }\end{array}$ & $\begin{array}{c}\text { 2-tailed } \\
\text { significance(P) }\end{array}$ \\
\hline PCV & 0.884 & 0.000 \\
MCV & 0.476 & 0.000 \\
MCH & 0.591 & 0.000 \\
MCHC & 0.198 & 0.001 \\
S.Iron & 0.242 & 0.000 \\
S.Ferritin & 0.017 & 0.776 \\
\hline
\end{tabular}

Discussion:

WHO defined Hb. cut off level is being used for our children. This cut off is based on the studies, mostly done in western children ${ }^{1,2}$. There is lack of adequate representative information regarding the haemoglobin level in south east asian region and socio demographic and nutritional factors influencing the haemoglobin level in children of our country and South East Asia. There is a unique study done by Faruk et al. in different socio demographic group of adolescent school boys in Dhaka city which estimated haemoglobin level in these groups and compared the influence of education of parents, occupation of parents, percapita income, nature of food consumed, nutrition status etc ${ }^{7}$. Present study was done in a section of children in the northern part of Bangladesh in Rangpur district. The mean age was $6.9 \pm 3.12$ yrs. This study doesn’t provide haematological values bellow 1 yr of age. Children of bellow 1 yr. was not included in the study because haemoglobin stabilizes to normal value at about 1 yr age ${ }^{8}$ and normal haemoglobin also appears by this age ${ }^{9}$.

It was found that the mean haemoglobin among the study population was $11.417 \mathrm{gm} / \mathrm{dl}(\mathrm{SD} ; \pm 1.07)$. The rang was $7.5 \mathrm{gm} / \mathrm{dl}$ to $14.7 \mathrm{gm} / \mathrm{dl}$. Percntile values are; $5^{\text {th }}$ percentile $=9.5 \mathrm{gm} / \mathrm{dl}, 25^{\text {th }}$ percentile $=10.8 \mathrm{gm} / \mathrm{dl}, 50^{\text {th }}$ percentile $=11.5 \mathrm{gm} / \mathrm{dl}, 75^{\text {th }}$ percentile $=12.1 \mathrm{gm} / \mathrm{dl}$ and $95^{\text {th }}$ percentile was $13.1 \mathrm{gm} / \mathrm{dl}$. Haemoglobin was found to be normally distributed in the study population. Median and mode was same(11.5gm). There was no skewness. WHO recommended lowest cutoff value for haemoglobin in children at sea level are: $11 \mathrm{gm} / \mathrm{dl}$ for 6 month to 59 month., $11.5 \mathrm{gm} / \mathrm{dl}$ for $5 y \mathrm{rs}$. to $11 \mathrm{yrs}$. and $12 \mathrm{gm} / \mathrm{dl}$ for 12 to $14 \mathrm{yrs}^{1,2}$. in comparison to that, the mean $\mathrm{Hb}$. in this study in different age group are; $10.73 \mathrm{gm} / \mathrm{dl}( \pm 0.99)$ for 1 to 4 yrs., 11.33gm/dl $( \pm 0.98)$

For 4 to 9 yrs. and 12.03gm/dl( \pm 0.94$)$ for 9 to 14 yrs. age. It indicates that mean haemoglobin is almost same as compared with WHO cut off value except for 1 to 4 yr age group which is lower in this study. In another study Frag et al. observed lower value in younger age group of children ${ }^{7}$. This difference is probably physiological. Nutrition seems doesn't have anything to do with this difference. Because in all age group mean Z-score for wt. for age was -2SD. More over it was found that there was no significant correlation between mean haemoglobin and mean Z-score for wt. for age $(r=0.005, P=0.927)$. There was no observed significant difference in $\mathrm{Hb}$. distribution in different sex groups in the study population. There was also no significant difference in mean haemoglobin among male and female children in different age groups. In this study mean haemoglobin for male children was, $11.4 \mathrm{gm} /$ $\mathrm{dl}( \pm 1.13)$ and that for female children was, $11.43( \pm 0.99)$. Mann and WhitneyU test shows no significant difference of mean haemoglobin between two $\operatorname{sexes}(\mathrm{P}=0.836)$. Hawkins et al. has shown in their study that sex difference in mean haemoglobin becomes apparent after 20 yrs of age ${ }^{10}$.WHO also has not recommended any different value for male and female children ${ }^{1}$. However there is significant age specific variation in mean haemoglobin.Significant difference was observed in mean haemoglobin among different age groups $(\mathrm{P}=0.01)$. This was noted in other studies also ${ }^{11,12,13,14}$.Age difference and age group variation is well documented by WHO and other studies ${ }^{1,15}$. Other factors influencing mean haemoglobin were family income, occupation of the parent, education of the parents and nutrition status. There was significant correlation between haemoglobin level and age $(r=0.478$, $\mathrm{P}=0.01)$. Iron status and nutritional status could be low in young children group. Mayer et al. observed that young children are vulnerable to anaemia, and nutritional anaemia is the most common cause ${ }^{16}$. Ahmed et al. in their study in Dhaka city in Bangladesh implicated pattern of foods as a significant factor for low hemoglobin in adolescent school boys ${ }^{7}$. How ever 
Duggan et al. found no correlation between biochemical iron status and protein energy nutritional status ${ }^{14}$. However other studies support the view that deficient iron intake is important contributor for low haemoglobin in infancy and early childhood ${ }^{17,18}$. In the studied population haemoglobin was normally distributed and there was no skewness. This indicates that haemoglobin values found in this study are normal for the studied population.

The WHO cut off value for haematocrit below which anaemia is considered to be present in children are as follows ${ }^{1}$;

Age group

Haematocrit

6mo. to $59 \mathrm{mo}$.

$5 y r$. to $11 \mathrm{yr}$.

0.34

$12 \mathrm{yr}$. to $14 \mathrm{yr}$.

0.36

In the present study mean PCV was $36.24 \%(S D ; \pm 3.31)$. In age groups in comparison to WHO cut off the mean PCV were: 1 to $4 \mathrm{yr}$; $34.35 \%( \pm 3)$, 4 to $9 \mathrm{yr}$; $36.03( \pm 3.04)$, and 9 to $14 \mathrm{yr} ; 38( \pm 3.05)$. This indicates that the children studied were not anaemic even as per WHO standard. More over there was a positive correlation found between $\mathrm{Hb}$. level and $\mathrm{PCV}(\mathrm{r}=.884$, $\mathrm{P}=.000)$. So, the haemoglobin value found in this group can be taken as normal. Mean value for MCV was $79.13 \mathrm{fl}(\mathrm{SD} ; \pm 8.2 \mathrm{fl})$, which is much above the lowest value (72fl) bellow which haemoglobin falls bellow the lowest cut for anaemia ${ }^{18}$. Domellof et al. has suggested - 2SD cut off value for MCV as 73 - $71 \mathrm{fl}$. in infants who are fed with iron fortified formula and ferritin > $10 \mathrm{ng} / \mathrm{L}^{19}$. In the present study MCV is much higher than these values. It can be presumed that the population studied is having normal MCV, so haemoglobin level found was the normal value of that population. Mean corpuscular haemoglobin (MCH) remains higher bellow 6 mo. of age. It falls progressively to reach it's nadir at 21 to 24 month of age. Duggan et al. found mean MCH in Asian healthy children at different age groups as follows $^{14}$; at $3-<6 \mathrm{mo}=25.7,6-<9 \mathrm{mo} .=24.1,9-$ $<12$ mo. $=23.7$ and at about $21-<24$ mo. $=21.9 p g$. The authors implicated it to the deficient iron intake. In the present study mean $\mathrm{MCH}$ was 24.82pg(SD; \pm 2.59 ) which is quiet higher than the Dggan's study and comparable to the value at $3-<$ mo. age group. This fact also support the assumption that the children of this study are not iron deficient. Age wise distribution of normal mean corpuscular haemoglobin concentration(MCHC) is ${ }^{9}$; 3mo. to yr. $=30-36 \mathrm{gm} /$ dl.RBC, 2yr. to 18 yr. = $31-37$ gm/dl.RBC. Mean $\mathrm{MCHC}$ in this study was $31.29 \mathrm{gm} \pm 1.84 \mathrm{gm} / \mathrm{dl}$.RBC. So, it is obvious that distribution of MCHC in this study is within normal limit. Mean MCHC was positively correlated with haemoglobin level $(r=0.198, \mathrm{P}=0.001)$. Serum iron was found to be positively correlated with level of haemoglobin in this study $(r=0.242, \mathrm{P}=0.000)$ The mean value was $59.72 \pm 32.94 \mu \mathrm{gm} / \mathrm{dl}$ which was also within normal limit(22 - $184 \mu \mathrm{gm} / \mathrm{dl})^{11}$. However iron depletion state is better reflected by serum ferritin level. WHO cut off value for serum ferritin is $15 \mathrm{ngm} / \mathrm{dl}$. Bellow this level iron store is considered to be depleted ${ }^{1}$. In the present study mean serum ferritin level in apparently non infectious children was 59.4ngm/dl. So, it can be assumed that the studied population was not iron depleted.

Conclusion: With all these observations and analysis it can be concluded that the normal mean haemoglobin of the study group of children (1yr to $14 \mathrm{yr}$. age) is $11.41 \mathrm{gm} / \mathrm{dl}$ with $\mathrm{SD}= \pm 1.07$. Median value is $11.5 \mathrm{gm} /$ dl. Percentile values are; $5^{\text {th }}$ percentile $=9.5 \mathrm{gm} / \mathrm{dl}, 50^{\text {th }}$ percentile $=11.5 \mathrm{gm} / \mathrm{dl}, 75^{\text {th }}$ percentile $=12.1 \mathrm{gm} / \mathrm{dl}$ and $95^{\text {th }}$ percentile $=13.1 \mathrm{gm} / \mathrm{dl}$. Haemoglobin is distributed normally in the studied population. No significant difference in mean haemoglobin between two sexes was observed. There was significant difference in mean haemoglobin between different age groups. Socio demographic factors that affect haemoglobin in a positive way are; total monthly income of the family, parental literacy and occupation of the parents. Important factor that was found to have no significant correlation with haemoglobin level was weight for age Z score. Haemoglobin distribution among 1yr. to $14 \mathrm{yr}$. age group of children was almost same as WHO set level.

Acknowledgement: The author is highly grateful to BMRC(Bangladesh Medical Research Council) for providing necessary fund for the study. Regards also goes to Prof. MA Mannan, former chairman department of haemato oncology, BSMMU for his encouragement.

\section{References:}

1. World Health Organization. Iron Deficiency Anaemia; Assessment, Prevention, and Control. A guide for programme managers. 2001. 
2. Benoist B, McLean With, Egli I, Cogswell M. World Health Organization. Worldwide prevalence of anaemia1993-2005. WHO Global Databaseon Anaemia. 2008.

3. Jackson RT. Haemoglobin Comparisons Between African American and Europian American Males with Haemoglobin values in the Normal Range. Journal of Human Biology. 1992; 4: $313-318$.

4. Lawson MS, Thomas M, Hardiman A. Iron status of Asian children aged 2 yrs. living in England. Arch. Dis. Child. 1998; 78: $420-426$.

5. Buetler W, West C. Haematologic difference between African - American whites: the roles of iron deficiency and á thalassaemia on haemoglobin levels and mean corpuscular volume. Blood. 2005; 106(2): 740 - 744.

6. Bao W, Dalferes ER, Srinivasan SR, Webber LS, Berenson GS. Normative distribution of Complete Blood Count from Early Childhood through Adolescence: The Bogalusa Heart Study. Preventive Medicine. 1993; 22: 825 - 837.

7. Ahmed F, Rahman A, Noor AN, Akhtaruzzaman M, Hughes R. Anaemia and vitamin A status among adolescent schoolboys in Dhaka City, Bangladesh. Public Health Nutrition. 2005;9(3):345 - 350.

8. Morton RE, Nysenbaum A, Price K. Iron status in first year of life. Journal of Paediatric Gastroenterology and Nutrition. 1988; 7:707 - 712 .

9. Glader B. The Anaemia. In: Behrman RE, Kliegman RM, Jenson HB, editors. Nelson Textbook of Paediatrics. Philadelphia: Saunders; 2004. p. 1605 - 1606.

10. Hawkins WW, Speck With, Leonard VG. Variation of Haemoglobin Level with Age and Sex. Blood. 1954; 9: 999 1007.
11. Viteri FE, Guzman MA. Haematological Status of Central American Population: Prevalence of Individuals with Haemoglobin levels bellow Normal. British Journal of Haematology. 1972; 23: 725 - 735.

12. Emond AM, Hawkins \&, Pennock C, Golding J. Haemoglobin and ferritin concentration in infants at 8 months age. Arch. Dis. Child. 1996; 74: 36 - 39.

13. Sherriff A, Emond A, Bell JC, Golding J. Should infants be screaned for anaemia? A prospective study investigating the relation between haemoglobin at 8,12 , and 18 months and development at 18 months. Arch. Dis. Child. 2001; 84:480 485.

14. Harris RJ, Armstrong D, Ali R, Loynes A. Nutrition survey of Bangladeshi children aged under 5 years in Londonborough of Tower Hamlets. Arch. Dis. Child. 1983; 58:428 - 432.

15. Quinto L, Aponte JJ, Sacarial J, Epasa M, Aide P, et al. Haematological and biological indices in young African children: in search of reference intervals. Tropical Medicine and International Health. 2006;11(11): 1741 - 1748.

16. DeMaeyer With, Adeils - Tegman M. The prevalence of Anaemia in the world. Rapp. Trimmest. Saint. Mond. 1985;38:302 - 316 .

17. Czajka - Narins DM, Haddy TB, Kallen DJ. Nutrition and social correlation in iron deficiency anaemia. The American Journal of Clinical Nutrition. 1978; 31:955 - 960.

18. Booth WI, Aukett MA. Iron deficiency anaemia in infancy and early childhood. Arch. Dis. Child. 1997; 76:549 - 554.

19. Domellof M, Dewey KG, Lonnerdal B, Cohen RJ, Hernell O. The diagnostic criteria for Iron Deficiency in Infants should be reevaluated. J. Nutr.2002;132: 3680 - 3686 